\title{
A Quazi Experimental Study to Develop Knowledge Regarding Hyperbaric Oxygen Therapy of Advanced Treatment for Tissue Injury and Infection among Selected B.B.Sc Nursing Students, Mins College, Latur
}

\author{
Azhagesan C*, Venugopal $\mathrm{K}$ and Padmavathi $\mathrm{R}$ \\ Maharashtra Institute of Nursing Sciences, India
}

*Corresponding author: Chinnasamy Azhagesan, Maharashtra Institute of Nursing Sciences, India; Email: chinnaala@gmail.com

\section{Research Article}

Volume 3 Issue 3

Received Date: May 17, 2019

Published Date: June 13, 2019

DOI: $10.23880 /$ nhij- 16000193

\section{Abstract}

Hyperbaric medicine, also known as hyperbaric oxygen therapy (HBOT), is the medical use of oxygen at a level higher than pressure, and is defined as a treatment in which a patient breathes $100 \%$ oxygen intermittently under a pressure of greater than sea level or our atmosphere. It has the capacity to promote the growth of new blood vessels, decreases swelling and inflammation deactivates toxins, increases the body s ability to fight infections, clears out toxins and metabolic waste products, and improve the rate of healing. This study Pretest-posttest control design was used subjects are randomly assigned to either the experimental or control group 50 samples selected and studying in B.B.Sc Nursing. Experimental group consists 25 and control group consists 25 samples. Simple random probability sampling technique is used. Experimental group pretest phase is 6.68 in control group pre-test phase mean is 6.8.Assessment of knowledge regarding HBOT after the implication of structure teaching programme. Finding shows that in experimental group post test phase was 21.76 and in control group mean of the post test phase is 12.8 The comparison the SD of pretest in experimental group and control group SD is 1.8 and 1.57 respectively and post-test in experimental and control group SD is 2.47 and 3.8. In experimental group the t test value of the present study is 1.78 . the table value of Df 48 is 2.01 . The value obtained by ' $t$ ' test is less than table value so hypothesis is proved and also in control group the ' $t$ ' test value of the present study is 1.12. Concluded that't' test value done to find the effectiveness of STP regarding HBOT

Keywords: Hyperbaric oxygen therapy; Students; Advance treatment and injury

\section{Introduction}

Oxygen therapy is one of the most critical considerations in the management of diseases crossing different medical and surgical specialties. Hyperbaric oxygen therapy (HBOT) is used in the treatment of certain conditions like decompression sickness, accidents, burns [1]. Severe Crush injuries of limbs seen typically in road, rail or industrial accidents, benefit from HBOT when selected with care. Radiation as part of cancer therapy 


\section{Nursing \& Healthcare International Journal}

may inadvertently cause damage to soft tissues \& bones; HBOT is of value in repair and control of symptoms. Severe soft tissue infections including the dreaded Gas gangrene is another well documented area of its utility. Thermal burns, Carbon monoxide poisoning, Smoke inhalation, caused by fire accidents have much to gain from hyperbaric oxygen therapy. Resistant bone infection or selected cases of severe fungal infections, HBOT is worthwhile. Plastic surgeons find it convenient to provide HBOT to patients with compromised skin flaps \& grafts Decompression sickness (DCS) may strike deep sea or fresh water divers. Researchers are actively investigating into utility of HBOT in several other medical disorders.

HBOT appears to be promising in Autism affected children, Paralytic Stroke rehabilitation, Traumatic brain injury, etc. Further research will determine the status of HBOT in these and several other disorders. HBOT in most cases supplements conventional treatment and not meant as Alternative therapy. The side effects are usually uncommon \& reversible. HBOT is given in "sittings" lasting between 60 to 120 minutes HBOT does add to treatment costs but reduces overall hospitalization bills, due faster healing, besides bettering outcomes in the seriously ill or chronic disorders.

\section{Problem Statement}

"Effectiveness of structured teaching program regarding hyperbaric oxygen therapy (HBOT) to develop knowledge of advanced treatment for tissue injury and infection among selected B.B.Sc Nursing students, MINS College, Latur".

\section{Objectives}

- To assess the level of knowledge among selected B.B.Sc Nursing students.

- To determine the effectiveness of STP regarding hyperbaric oxygen therapy.

- To find the association between pre-test and post-test score.

\section{Need for Study}

Oxygen therapy is one of the most critical considerations in the management of diseases crossing different medical and surgical specialties. But this is one subject which remains poorly understood and inadequately practiced. Invariably, enormous errors are committed in the use of oxygen. Oxygen prescription often comprises of a single written word 'oxygen'19 Frequently, it is administered merely on verbal orders. Reports on assessment of uses and misuses of oxygen are almost universal including those from the developed countries of the West. Knowledge of the technique of oxygenation is a key to the proper care [2,3].

\section{Material \& Method}

\section{Effectiveness}

Effectiveness is effect of structural teaching programme on hyperbaric oxygen treatment for selected B.Bsc Nursing students $[4,5]$.

\section{Structured Teaching Programme}

It refers system of planned instruction desired to impart information in order to gain knowledge regarding hyperbaric oxygen treatment for selected B.Bsc Nursing students.

\section{Hyperbaric 0xygen Treatment}

It is defined as a treatment in which a patient breathes $100 \%$ oxygen intermittently under a pressure of greater than sea level or atmosphere 20 .

\section{Knowledge}

It refers to correct responses towards the items of the knowledge questionnaire regarding hyperbaric oxygen treatments.

\section{Selected B.Bsc Nursing Students}

It refers to students who are studying in B.Bsc Nursing in MINS College, Latur.

\section{Hypothesis}

H1: There will be significant increase in knowledge regarding hyperbaric oxygen treatment.

H2: There will be significant association in the level pretest and post test score on hyperbaric oxygen treatment.

\section{Research Approach}

Assess effectiveness of STP on hyperbaric oxygen treatment to develop knowledge advanced treatment for injury and infection among B.Bsc Nursing student an experimental approach (Table 1). 


\section{Nursing \& Healthcare International Journal}

\section{Research Design}

\begin{tabular}{|c|c|c|c|}
\hline Group & Pre-test & Intervention & Post test \\
\hline Experimental & $\mathrm{O}_{1}$ & $\mathrm{X}$ & $\mathrm{O}_{2}$ \\
\hline Control & $\mathrm{O}_{1}$ & - & $\mathrm{O}_{2}$ \\
\hline
\end{tabular}

Table 1: Hyperbaric oxygen treatment among selected nursing students.

01- Pre-test on Hyperbaric oxygen treatment among selected B.Sc. Nursing student.

$\mathrm{X}$ - Intervention (structured teaching programme) on hyperbaric oxygen treatment.

02- Post-test on Hyperbaric oxygen treatment among selected B.BSc Nursing student.

\section{Research Setting}

MINS College, Latur.

\section{Sample Size}

In present study sample consists of 50 selected students studying in B.Bsc Nursing. Experimental group consists 25 and control group consists 25 samples.

\section{Sampling Technique}

Sampling technique used simple random probability sampling technique.

\section{Sampling Criteria}

The samples were selected with the following set of criteria during the period of study.

\section{Inclusive Criteria}

- Students who are present during period of study.

- Selected students only from B.BSc Nursing.

- Those who are willing to participate in the study.

\section{Exclusive Criteria}

- Students who are not willing to participate in the study.

- Students who are not selected during the randomization technique.

\section{Description of Tool}

Section-A: Personal data consists of 5 items which includes Age, Gender, Type of family, Place of living, , Family Income, etc.

Section-B: A Structured Knowledge Questionnaire was prepared consisting of 20 items of knowledge about hyperbaric oxygen treatment.

\section{Inferential Statistics}

Paired 't-'test and student ' $\mathrm{t}$ ' test will be used to find out the effectiveness of STP on hyperbaric oxygen treatment to develop knowledge of advanced treatment for injury and infection among B.BSc Nursing students (Table 2).

\begin{tabular}{|c|c|c|c|}
\hline S.No & $\begin{array}{c}\text { Demographic } \\
\text { Variable }\end{array}$ & Frequency & Percentage \\
\hline \multirow{5}{*}{1} & \multicolumn{3}{|c|}{ Age group } \\
\hline & a. $17-18$ yrs & 5 & $10 \%$ \\
\hline & b. $18-19$ yrs & 21 & $42 \%$ \\
\hline & c. $19-20$ yrs & 17 & $34 \%$ \\
\hline & d. Above 20 yrs & 7 & $14 \%$ \\
\hline \multirow{4}{*}{2} & \multicolumn{3}{|c|}{ Gender } \\
\hline & a. Male & 20 & $40 \%$ \\
\hline & b. Female & 30 & $60 \%$ \\
\hline & c. Trans gender & 0 & 0 \\
\hline \multirow{5}{*}{3} & \multicolumn{3}{|c|}{ Place of Living } \\
\hline & a. Urban & 22 & $44 \%$ \\
\hline & b. Rural & 13 & $26 \%$ \\
\hline & c. Semi urban & 10 & $20 \%$ \\
\hline & d. Other & 5 & $10 \%$ \\
\hline \multirow{5}{*}{4} & \multicolumn{3}{|c|}{ Family Income per month } \\
\hline & a. $5000-10000 \mathrm{Rs}$ & 7 & $14 \%$ \\
\hline & b. $10000-15000 \mathrm{rs}$ & 6 & $12 \%$ \\
\hline & c. $15000-20000 \mathrm{rs}$ & 9 & $18 \%$ \\
\hline & d. Above $20000 \mathrm{rs}$ & 28 & $56 \%$ \\
\hline \multirow{5}{*}{5} & \multicolumn{3}{|c|}{ Type of family } \\
\hline & a. Single family & 34 & $68 \%$ \\
\hline & b. Joint family & 14 & $28 \%$ \\
\hline & c. Extended family & 0 & 0 \\
\hline & d. Nuclear family & 2 & $4 \%$ \\
\hline
\end{tabular}

Table 2: Sample data describe the majority.

First section sample data describe the majority of 21 sample belongs to age group 18-19 yrs (42\%), 5 sample belongs to group 17-18yrs (10\%). The majority of 30 sample are female (60\%) and 20 sample are male (40\%). The data describe that 22 sample lives in urban area (44\%), 10 samples lives in other above (10\%) in total 50 samples.

The majority of 28 samples have family income above 20,000 (56\%), 6 samples family income is $10,000-15,000$ $(12 \%)$. The majority of 34 samples are in single family (68\%), 2 samples are belong to nuclear family (4\%) and no sample in extended family (Table 3 ). 
Nursing \& Healthcare International Journal

\begin{tabular}{|c|c|c|c|c|c|}
\hline \multirow{2}{*}{ S.No } & \multicolumn{2}{|c|}{ MEAN } & \multicolumn{2}{c|}{ SD } \\
\cline { 2 - 6 } & Group & Pre-test & Post-test & Pre-test & Post-test \\
\hline 1 & Experimental group & 6.68 & 21.76 & 1.8 & 2.47 \\
\hline 2 & Control group & 6.8 & 12.08 & 1.57 & 3.8 \\
\hline
\end{tabular}

Table 3: Comparison of mean \& standard deviation of pre-test and post level of knowledge regarding HBOT among selected B.B.Sc Nursing students in experimental group and control group.

The above data describe of comparison of pre-test and post-test in experimental and control group, which is mean having 6.68 and 6.8 respectively in pre-test. In post- test mean in experimental and control group is 21.76 and 12.08 (Figures $1 \& 2$ ).

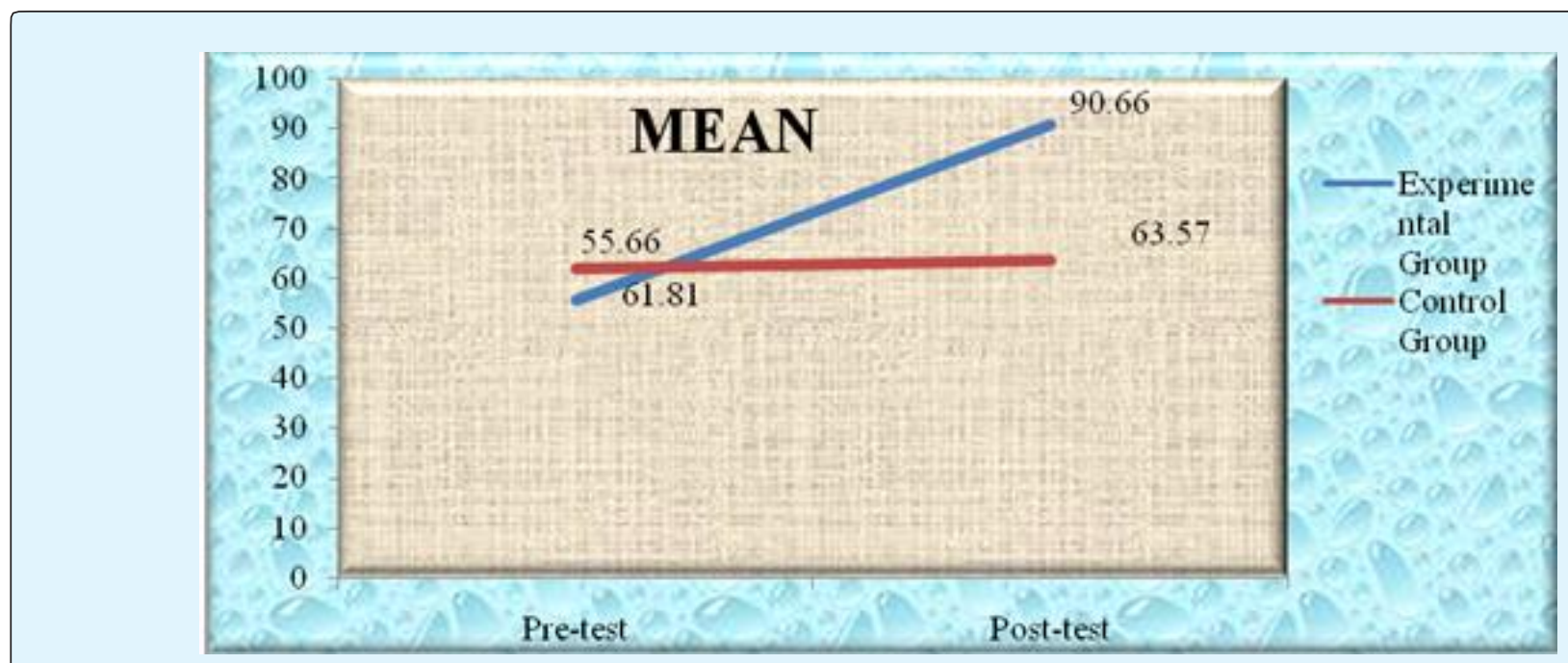

Figure 1: Comparison of pre-test and post-test in experimental and control group.

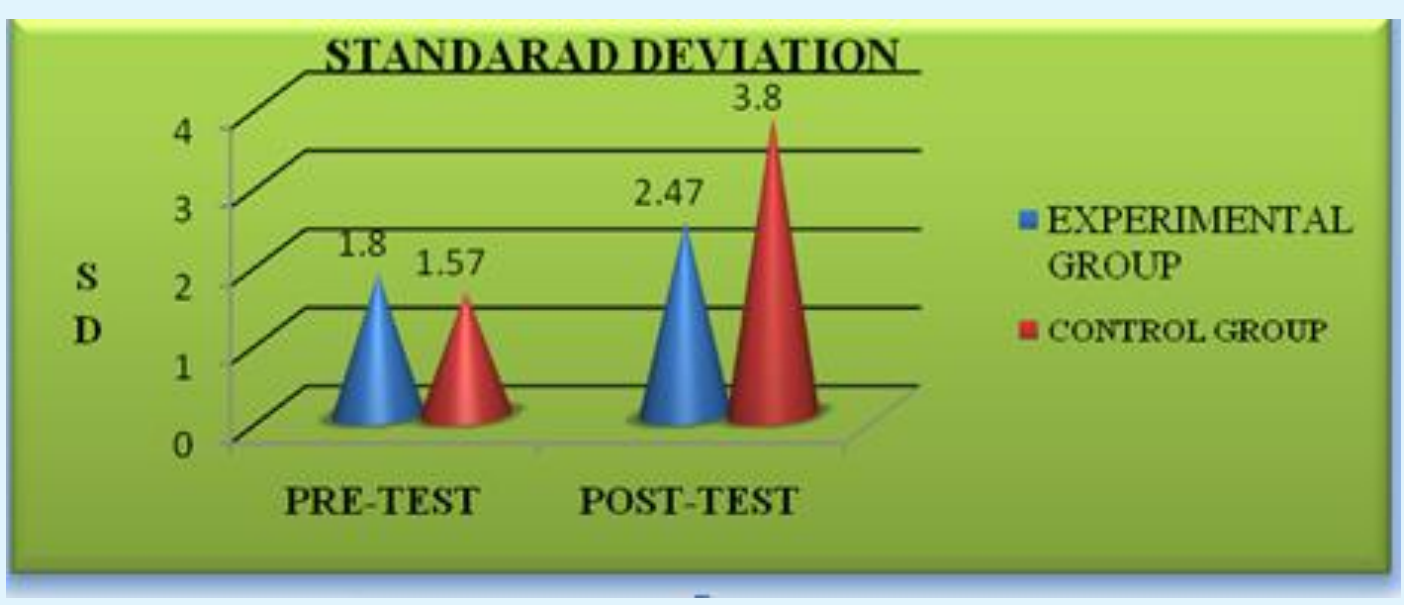

Figure 2: Comparison of standard deviation of experimental and control group.

The data mentioned that score of knowledge of in pretest in experimental group and control group SD is 1.8 and 1.57 respectively and post-test in experimental and control group SD is 2.47 and 3.8. Comparison of ' $\mathrm{t}$ ' test with experimental and control group (Table 4). 


\section{Nursing \& Healthcare International Journal}

\begin{tabular}{|c|c|c|c|c|c|c|c|c|c|}
\hline \multicolumn{9}{|c|}{ Experimental group } & \multicolumn{4}{c|}{ Control group } \\
\cline { 1 - 7 } SR.NO & & MEAN & MEAN \% & SD & \multirow{2}{*}{ T'-TEST VALUE $^{*}$ MEAN } & MEAN \% & SD & $\begin{array}{c}\text { T'-TEST } \\
\text { VALUE }\end{array}$ \\
\hline 1 & Pretest & 6.68 & 55.66 & 1.8 & \multirow{2}{*}{1.78} & 6.8 & 61.818 & 1.6 & \\
\hline 2 & Posttest & 21.76 & 90.66 & 2.5 & & 12.08 & 63.57 & 3.8 & 1.12 \\
\hline
\end{tabular}

Table 4: Comparison of mean, mean\%, standard deviation and t test value of pre-test and post level of knowledge regarding HBOT among selected B.Bsc Nursing students in experimental group and control group.

Findings of section-3 show that comparison of mean of pre and post-test of knowledge regarding HBOT among selected B.BSC student in experimental group and control group .in experimental the mean value of pretest is 6.68 and the mean of post-test value is11.76 while in control group the mean of pre-test is 12.8 .

Finding describes that comparison of pre-test and posttest in experimental and control group which is having mean percentage $55.66 \%$ and $61.81 \%$ respectively and the value of mean percentage of post-test in experimental of control group of post-test in experimental and control group $90.66 \%$ and $63.57 \%$ respectively.

The comparison the SD of pre-test in experimental group and control group SD is 1.8 and 1.57 respectively and post-test in experimental and control group SD is 2.47 and 3.8.

\section{"t" Test Value}

The ' $t$ ' test value of the present study is 1.12 . The table value of df (degree of freedom) 48 is 2.01 . The value obtained by $t$ test is less than table value so hypothesis is proved.

The table shows data comparing the score of knowledge in pre-test and post-test of experimental group which having mean 6.68 , mean\% 55.66 and SD 1.8 as well as the post-test mean is 21.76 , mean\% is 90.66 and SD is 2.47 .

\section{Conclusion}

The ' $t$ ' test value done to find the effectiveness of STP regarding HBOT to selected B.B.Sc Nursing students in MINS College, Latur and that revealed there will be significant association in the level pre-test and post test score on HBOT and educating the student on HBOT by using STP has shown a significant effect in improving their knowledge and research hypothesis is proved.

\section{References}

1. Barber C (2012) Health Management in Health Care Environments. BJN 21(5): 299-302.

2. Chinnasamy Azhagesan. Knowledge Regarding Phototherapy for Neonatal Jaundice among Third Year B. Sc. Nursing Students.

3. Waugh A, Grant A (2010) Ross and Wilson Anatomy and Phyisiology in Health and Illness, 11 ${ }^{\text {th }}$ (Edn.), Churchill Livingstone Elsevier, pp: 512.

4. (2013) The Importance of Oxygen.

5. (2013) Biological Action. 